\title{
Optimality-Theoretic Pragmatics Meets Experimental Pragmatics
}

\author{
Reinhard Blutner
}

ILLC, University of Amsterdam

The main concern of this article is to discuss some recent findings concerning the psychological reality of optimality-theoretic pragmatics and its central part bidirectional optimization. A present challenge is to close the gap between experimental pragmatics and neo-Gricean theories of pragmatics. I claim that OT pragmatics helps to overcome this gap, in particular in connection with the discussion of asymmetries between natural language comprehension and production. The theoretical debate will be concentrated on two different ways of interpreting bidirection: first, bidirectional optimization as a psychologically realistic online mechanism; second, bidirectional optimization as an offline phenomenon of fossilizing optimal form-meaning pairs. It will be argued that neither of these extreme views fits completely with the empirical data when taken perse.

\section{Introduction}

Recent approaches to experimental pragmatics (e.g. Noveck \& Sperber, 2005) are mainly concentrated on the investigation of scalar implicatures. Characteristically, the interpretive perspective (hearer's view) is taken in this research. A theoretical main issue is to decide between two rivalling theories: Sperber \& Wilson's (1986/1995) Relevance Theory (RT) and Levinson's (2000) theory of presumptive meanings or generalized conversational implicatures (GCIs). Levinson claims that GCIs are calculated automatically - i.e. without demanding much processing resources. In contrast, RT argues that the calculation is controlled and is strongly influenced by the available processing resources. Neo-Griceans (Atlas \& Levinson, 1981; Horn, 1984; Blutner, 1998; e.g. Atlas, 2005; Horn, 2005) are normally ignored in this research. A defense for this pretermission is that neo-Gricean theories are normative theories that do not directly make predictions about processing. Unfortunately, this argument 
exaggerates the philosophical issue of distinguishing between the normative and the naturalistic realm. Surely, these two aspects of understanding human actions can be clearly separated from each other. However, that does not mean they predict different action patterns in most cases. The idea of a rational world isn't so irrational to be excluded in ordinary affairs. Evolutionary game theory has presented us with many examples demonstrating that the reasonable is naturally arising (Axelrod, 1984). In other words, though there is a philosophical gap between Gricean pragmatics as a normative theory and experimental pragmatics as a scientific, explanatory theory of natural language interpretation, there is no deep empirical conflict between interpretation oriented pragmatics and speaker ethics. It seems the speaker better be cooperative (or pretend to be cooperative) if she wants to use language to bring about effects in hearers.

The aim of this article is to close the gap between experimental pragmatics and neo-Gricean theories of pragmatics. The version of neo-Gricean pragmatics I will consider here is called optimality-theoretic (OT) pragmatics. While the automatic/controlled issue of processing has dominated the recent theoretical debate, OT pragmatics will raise several additional issues. One new issue concerns the asymmetries between comprehension and production. How to explain the experimentally observed asymmetries and what is their status in theories of language acquisition? Seeing comprehension and production as different optimization processes, a further research topic concerns the question of how the two optimization processes are integrated with each other (bidirectional optimization). That relates to the psychological reality of bidirectional optimization in the domain of pragmatics. Another new issue concerns the nature of conventionalization (or fossilization) in pragmatics.

The following quotation from Noveck \& Sperber (2005) fully applies to the raised new pragmatic issues.

Properly devised experimental evidence can be highly pertinent to the discussion of pragmatic issues, and pragmatics might greatly benefit from becoming familiar with relevant experimental work and from contributing to it. (Noveck \& Sperber 2005, p. 210)

Without careful experimental research linguistic pragmatics cannot really mature and will remain in a phase of rampant speculation and questionable research habits.

Optimality theory (OT) will be used in this article both in the broad sense of a general methodology dealing with resolving conflicting constraints by using universal optimization procedures and in the narrower sense of developing an explicit model that concern the essentials of neo-Gricean pragmatics. 
In the following sections we assume some familiarity with the basic conceptions of OT pragmatics as provided in the first paper of the present collection. Further, I assume some knowledge about the three main views conforming to a naturalistic pragmatics: RT, Levinson's (2000) theory of presumptive meanings, and the neo-Gricean approach. In the first contribution to this volume, I have demonstrated how the idea of optimal interpretation can be used to restructure the core ideas of these three different approaches. Section 2 explains the idea of fossilization. It is pointed out how the general setting of cultural evolution can help to make this idea precise. Further, a series of important theoretical problems is raised - mainly concerning the distribution of labor between online processes (optimization procedures) and offline processing (fossilization processes). In section 3, I discuss several experimental findings and come to a preliminary conclusion about the relationship between online processes and fossilization phenomena. Section 4 draws some general conclusions relating to a deeper understanding of the idea of naturalization and (cultural) embodiment in the context of natural language interpretation.

\section{Fossilization: a bidirectional OT account}

In the first contribution to this collection, I have introduced weak bidirectionality and it was illustrated how this solution concept explains Horn's division of pragmatic labour. If we assume that the optimization procedure is supplemented by a system of ranked (heuristic) constraints - in order to provide the content of the optimization - then Horn's R-principle/Q-principle is in exact correspondence to interpretive/expressive optimization. Further, the moduloclause in the formulation of the Q-/R-principle is explicitly expressed by the recursive term in formalism defining weak bidirectionality.

An important question concerns the status of the theory with regard to synchrony versus diachrony. Obviously, both RT and Levinson's theory of presumptive meanings take the synchronic view and both suggest a model of online language interpretation. Within the neo-Gricean camp, the situation is not so clearly decided. Whereas researchers like Atlas (2005) take a synchronous view, researchers like Horn (1984) clearly emphasize the diachronic perspective.

In the framework of OT pragmatics it is very natural to take weak bidirection as expressing a basic principle of natural language change. As a consequence, bidirectional optimization has nothing to do with online processes that run during normal language interpretation/production. Rather, the results of bidirectional optimization are routinized or fossilized - a phenomenon that takes place on an evolutionary time scale. Hendriks et al. (to appear) put this point as follows: 
On Blutner and Zeevat's evolutionary view of bidirectionality, form-meaning pairs that have been determined by bidirectional optimization constitute fixed relations to a learner who sets out acquiring the language. No learner, indeed no user of the language, needs to perform a bidirectional computation for any form-meaning pair she encounters.

In contrast to this view there are representatives of OT pragmatics who suggest a procedural formulation of week bidirection and propose it as a realistic model of natural language interpretation and/or natural language production (e.g. Zeevat, 2000; Jäger, 2002; Beaver \& Lee, 2004; Hendriks \& Spenader, 2005/2006). This position is also taken in Hendriks et al. (to appear):

However, we take the position that bidirectionality is not in the first place an evolutionary mechanism. Some form-meaning pairings have not been fossilized or automatized, but must be computed anew in a given situation. This view of bidirectionality raises the question of whether bidirectionality is a property of an individual's linguistic performance from the onset of language acquisition, or whether it is acquired or instantiated at some later time. We believe that the latter is the case. Whenever a bidirectional pair has to be computed online in a given situation, it is necessary for the hearer to realize which options were available to the speaker, and also to realize that the speaker's eventual choice is codetermined by the speaker's assumption that the hearer is able to share his perspective. It is to be expected that such online computation requires considerable cognitive resources.

In section 3, I will discuss recent empirical studies that relate to the two different positions.

In natural language pragmatics, the idea of fossilization was introduced first in Geis \& Zwicky's (1971) paper about 'invited inferences' as a mechanism of conventionalization for implicatures. A closely related approach is Morgan's (1978) theory of short-circuited implicatures where some fundamentally pragmatic mechanism has become partially grammaticalized. Leaning on this idea, Horn \& Bayer (1984) propose an elegant account of so-called neg-raising, "the availability (with certain predicates) of lower clause understandings for higher clause negations" (p. 397). There is a principal difficulty for nonsyntactic treatments of these neg-raising interpretations. The difficulty has to do with the existence of lexical exceptions to neg-raising, i.e. we find pairs of virtual synonyms of which one member allows the lower clause understanding and the 
other blocks it. ${ }^{1}$ Horn \& Bayer (1984) argue that conversational implicatures may become conventionalized ("pragmatic conventions") and this conventionalization sanctions neg-raising. The short-circuiting of implicatures as a matter of convention has important empirical consequences, some of them we will discuss in the following section. ${ }^{2}$

In an early paper, Cole (1975) investigates similar phenomena in the lexical realm. Calling the conventionalization phenomenon "lexicalization of contextual meaning" he makes quite clear that the relevant conventions are built on the basis of particularized conversational implicatures (i.e. what Levinson (2000) calls utterance token meanings). Further, he proposes a diagnostics for discriminating between implicatures proper and their lexicalized counterpart. This may help to clarify the synchronic/diachronic status of conversational implicatures.

Traugott and her colleagues (e.g. Traugott, 1989; Traugott \& Dasher, 2005) applied the idea of fossilization to explain language change. According to this model innovation may arise in the individual and spread or propagate through the community. In their invited inferencing theory of semantic change, Traugott and co. postulate a cycle starting with coded meaning, exploiting particularized conversational implicatures, transforming these implicatures into generalized conversational implicatures (= conventionalization), and finally resulting in new coded meanings (cf. Traugott \& Dasher, 2005). Figure 1 shows a simplified picture of this model.

${ }^{1}$ One of Horn \& Bayer's (1984) examples concerns opinion verbs. For instance, Hebrew xogev 'think' permits NR readings while maamin 'believe' does not. Interestingly, the opposite pattern obtains in Malagasy. In French souhaiter 'hope, wish' exhibites negraising, but its near-synonym espdrer does not - although it's Latin etymon sperare did. (cited after Horn \& Bayer, 1984, p. 400).

${ }^{2}$ For example, we expect to find differences between speakers and between languages as to just which conventions of usage are operative. And exactly this happens as it is pointed out in Horn \& Bayer (1984). 


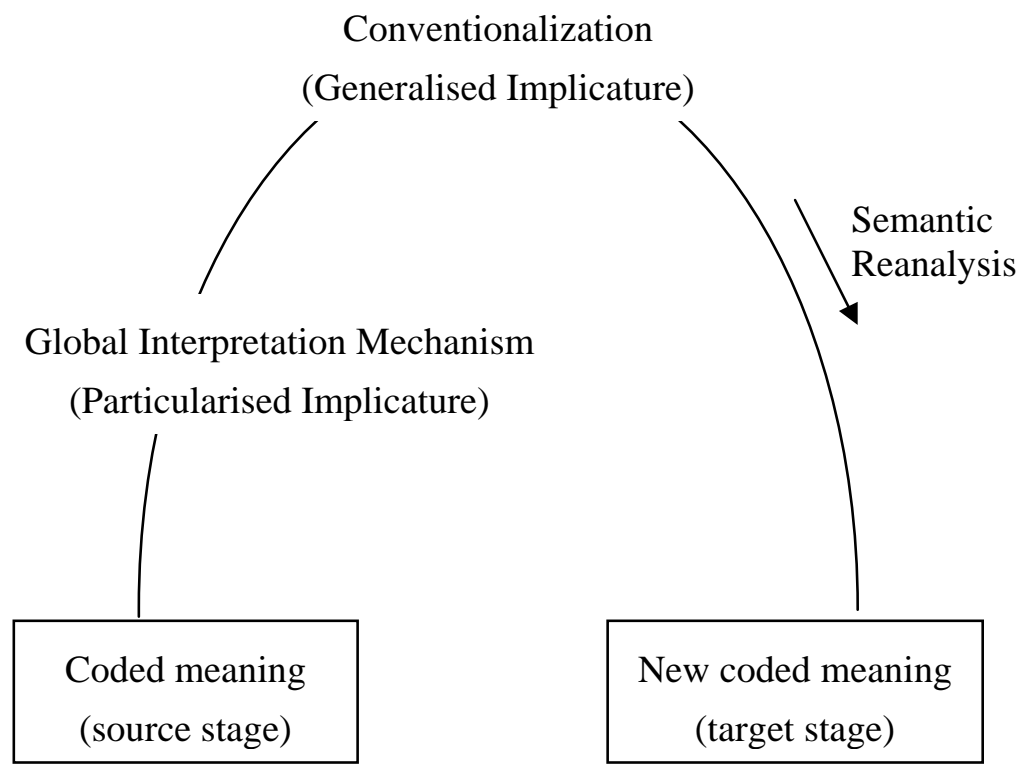

Figure 1: Simplified representation of the invited inferencing theory of semantic change (see Traugott \& Dasher 2005: 38)

In the domain of syntax, Levinson (2000) und Mattausch (2004) used very the same idea for explaining the development of binding principles.

I will use the term fossilization here in a very broad sense that covers the whole spectrum of the mentioned phenomena. It stands for processes of individual fossilization or routinization that take place in individual language acquisition, i.e. on a time scale of seconds, hours and months. What's more it stands for social processes of cultural fossilization that take place in language change on a historical time scale of years up to centuries; the relevant mechanism is iterated learning/cultural evolution.

In OT pragmatics, fossilization relates to a transformation of knowledge systems. As we have seen in the first contribution to this volume, it is possible to describe the same solution space in two different ways. In the first case (Figure 2a, p. 11) unidirectional optimization (either hearer or speaker perspective) is sufficient to calculate the solution pairs. It is plausible to assume that this kind of OT systems can be used to construct cognitively realistic models of online, incremental interpretation (see Blutner, 2006, 2007). The second case (Figure $2 \mathrm{~b}, \mathrm{p} .11$ ) is using the recursion of weak bidirection (super-optimality) and has a completely different status. Because of its strictly non-local nature the proposed 
algorithms that calculate the super-optimal solutions do not even fit the simplest requirements of psychologically realistic models of online, incremental interpretation (Zeevat, 2000; Beaver \& Lee, 2004). ${ }^{3}$

The proper understanding of weak bidirection and super-optimality relates best to an off-line mechanism that is based on bidirectional learning (Blutner, Borra, Lentz, Uijlings, \& Zevenhuijzen, 2002; Benz, 2003; Van Rooy, 2004; Benz, 2006). In these approaches the solution concept of weak bidirection is considered as a principle describing the results of language change: superoptimal pairs emerge over time in language change. This relates to the view of Horn (1984) who considers the Q and the I principle as diametrically opposed forces in language change, and it conforms to the good old idea that synchronic structure is significantly informed by diachronic forces.

For the sake of illustration let's go back to the example illustrated in Figure 2 of the first contribution to this collection (p. 12). Let's assume a population of agents who realize speaker- and hearer strategies based exclusively on the markedness constraints $\mathrm{F}$ and $\mathrm{M}$. In this population each content is expressed in the simplest way $\left(f_{1}\right)$ and each expression is understood in the simplest way $\left(m_{1}\right)$. Let's assume further that these agents communicate with each other. When agent $\mathrm{x}$ is in the speaker role and intends to express $m_{1}$, then expressive optimization yields $f_{1}$. Agent y is a hearer who receives $f_{1}$ and, according to interpretive optimization, he gets the interpretation $m_{1}$ - hence the hearer understands what the speaker intends: successful communication. Now assume the speaker wants to express $m_{2}$. With the same logic of optimization he will produce $f_{1}$ and the agent $y$ interprets it as $m_{1}$. In this case, obviously, the communication is not successful. Now assume some kind of adaptation either by iterated learning or by some mutations of the ranked constraint system (including the linking constraints). According to this adaptation mechanism the expected 'utility' (how well they understand each other in the statistical mean) can improve in time. In that way a system that is evolving in time can be described including its special attractor dynamics. In each case there is a stabilizing final state that corresponds to the system of Figure 2a (p. 12) where the two Levinsonian (2000) constraints $\mathbf{I}(=[\mathrm{F} \rightarrow \mathrm{M}])$ and $\mathbf{M}(=[\mathrm{F} \rightarrow \mathrm{M}])$ outrank the rest of the constraints. It is precisely this system that reflects Horn's division

\footnotetext{
3 There are several arguments why bidirectional OT cannot yield an online mechanism of linguistic competence. Beaver \& Lee (2004) argue that if more rounds of optimization are allowed, the bidirectional OT-model severely overgenerates in the sense that in later rounds peculiar new form-meaning pairs will emerge as winners. Before the Beaver \& Lee paper, Zeevat (2000) argued against the symmetric view of OT pragmatics starting from the famous rat/rad problem and its pragmatic counterparts.
} 
of pragmatic labour. The only condition we have to assume is that the marked contents are less frequently expressed than the unmarked contents. ${ }^{4}$

Hence, the important insight is that a system that is exclusively based on markedness constraints such as in Figure 2b (p. 12) is evolutionary related to a system based on highly ranked linking constraints such as in Figure 2a. It is opportune to present some more details at this point. Our own simulation studies (Blutner et al., 2002) have provided the following results assuming the three different strategies illustrated in Figure 2. Here the Horn-strategy describes the famous pattern of iconicity (Horn's division of pragmatic labour). The antiHorn-strategy describes a kind of anti-iconicity, and the Smolensky-strategy describes the presumed initial state of a learner where unmarked forms and unmarked meanings are preferred simultaneously.

Horn-Strategy

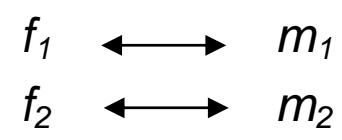

$\left\{\mathrm{F} \rightarrow \mathrm{M},{ }^{*} \mathrm{~F} \rightarrow{ }^{*} \mathrm{M}\right\}>>\ldots$
Anti-Horn-Strategy

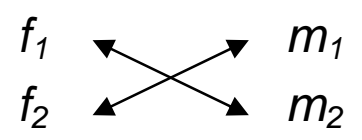

$\{\mathrm{F} \rightarrow * \mathrm{M}, * \mathrm{~F} \rightarrow \mathrm{M}\}>>\ldots$

\section{Smolensky-Strategy}

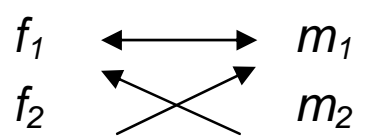

$\left\{K_{\mathrm{F}}, \mathrm{K}_{\mathrm{M}}\right\}>>\ldots$

Figure 2: Three different strategies - based on the indicated three different rankings of the constraints

- Horn- und anti-Horn-strategies are the only evolutionary stable strategies.

- If the initial state represents a uniform Smolensky-population, then the systems develops into

- a pure Horn-population, assumed the frequency of the realization of $\mathrm{m}_{1}$ is higher than that of $\mathrm{m}_{2}: \mathrm{P}\left(\mathrm{m}_{1}\right)>\mathrm{P}\left(\mathrm{m}_{2}\right)$

- a pure anti-Horn-population, assumed the frequency of the realization of $\mathrm{m}_{2}$ is higher than that of $\mathrm{m}_{1}: \mathrm{P}\left(\mathrm{m}_{2}\right)>\mathrm{P}\left(\mathrm{m}_{1}\right)$

- The corresponding proposition is true if the initial state represents a mixed population

\footnotetext{
${ }^{4}$ For more discussion of the role of frequencies in an evolutionary setting cf. Stalnaker (2006). The general conclusion is that the solution concept of weak bidirection can be seen as a rough first approximation to the more adequate solution concepts of evolutionary game theory that describe the results of language change.
} 
Hence, the probabilities for the situations that are described, i.e. $\mathrm{P}\left(m_{1}\right), \mathrm{P}\left(m_{2}\right)$, are decisive for the result. The classical pattern of iconicity is predicted only in cases where the unmarked situation has the highest probability. McCawley (1978) has listed numerous cases of constructional iconicity in the lexicon. Krifka (2007) has observed that the phenomenon is the decisive factor in determining the precise/vague interpretation of measure expressions.

Interestingly, there are also examples of anti-iconicity. They are found in connection with semantic broadening where the initial meaning is described as that of an ideal shape, figure or state. A good example can be found in Dutch, where besides the preposition om (= Engl. round; German um) the expressions rond and rondom are in use. The expression rond is a word borrowed from French. It refers to the ideal shape of a circle. Starting with its appearance it comes in competition with the original (and unmarked) expression om. The results is a division of labour as demonstrated in the following examples (cf. Zwarts, 2003, 2006):
(1) a. Ze zaten rond (?om) de televisie
'They sat round the television'
b. Een man stak zijn hoofd om (?rond, ?rondom) de deur 'A man put his head round the door'
c. De auto reed om (?rond, ?rondom) het obstakel heen 'The drove round the obstacle'
d. het gebied rondom (?om) het stadje 'the area round the little town'

According to the principle of iconicity we would expect that the unmarked form $(\mathrm{om})$ is paired with the ideal of the circle shape and the marked form (rond) with the detour interpretation. ${ }^{5}$ However, the opposite is true. I think there is a simple explanation for this fact: ideal shapes/situations are much less frequent then nonideal situations; hence, since $\mathrm{P}\left(m_{1}\right)<\mathrm{P}\left(m_{2}\right)$, the present evolutionary approach predicts anti-iconicity.

I think these examples and many other examples in the area of lexical pragmatics (e.g. Blutner, 1998; Wilson, 2003) strongly suggest the reality of fossilization. Accepting that both possibilities are real to some extend - the online calculation of implicatures and the access of their fossilized counterparts, the question concerns the distribution of labor between online processes

\footnotetext{
5 The assumption that the ideal path description (circle) is realizing the unmarked interpretation and the detour interpretation is realizing the marked interpretation is justified by independent thoughts about the preference of the logically strongest interpretation (e.g. Dalrymple, Kanazawa, Kim, Mchombo, \& Peters, 1998).
} 
(calculating optimal outcomes) and offline processing (fossilization processes). We can ask this question for standard scalar implicatures, as well as for other types of pragmatic inferences. In the next section I will review some experiments that are claimed to decide the issue. These experiments are closely related to the issue of asymmetries between comprehension and production processes.

\section{Asymmetries between natural language comprehension and production}

It's a common observation that we often are not able to produce what we can understand. The opposite situation, where we are able to produce a certain expression but unable to understand, it is observed much less often. The phenomenon of aphasia gives a feasible illustration of the existence of both kinds of asymmetries (e.g. Jakobson, 1941/1968). Likewise, in the domain of language acquisition both sides of the phenomenon can be detected. It is well known that children's ability in production lags dramatically behind their ability in comprehension (e.g. Benedict, 1979; Clark, 1993). It was only recently that attention was devoted to the opposite case where children's comprehension performance lags years behind their ability of production (cf. Hendriks \& Spenader, 2005/2006) .

There are three different ways to deal with these observations. The first approach is to assume dissociation between a comprehension grammar and a production grammar. Unfortunately, this account requires some ad hoc stipulations which conflict with general assumptions of parsimony.

The second approach is to assume different processing restrictions for production and comprehension. Joshi (1987) was possibly the first who discussed the asymmetry issue from the viewpoint of artificial intelligence:

Comprehension and generation, when viewed as functions mapping from utterances to meanings and intentions and vice versa, can certainly be regarded as inverses of each other. However, these functions are enormously complex and therefore, although at the global level they are inverses of each other, the inverse transformation (i.e., computation of one function from the other) is not likely to be so direct. So, in this sense, there may be an asymmetry between comprehension and generation even at the theoretical level. (Joshi 1987, p. 183)

Joshi further suggests (p. 184) that the human generation mechanism involves some monitoring of the output, presumably by the comprehension mechanism. 
A corresponding monitoring (by generation) is not assumed for the human comprehension mechanism.

The third way of dealing with the asymmetry follows from an optimization approach. This was first demonstrated by Smolensky (1996). As we have seen in the previous sections, natural language production in OT goes from a given interpretation to an optimal expression and natural language comprehension goes from a given expression to an optimal interpretation. It is these different directions of optimization which impose different boundary conditions on the process of optimization. As a result, the same system of constraints and the same constraint hierarchy can account for the observed asymmetry, without taking recourse to multiple grammars or different processing restrictions for production and comprehension.

In this section I will discuss asymmetries between comprehension and production in the context of recent experimentation. The natural language expressions investigated are pronouns, reflexives, referential and quantifying expressions - the latter in connection with scalar implicatures. The fundamental questions asked are twofold:

(i) How to explain the observed differences between comprehension and production in a certain stage of development?

(ii) What is the mechanism that handles how to overcome the gap between comprehension and production during natural language acquisition?

OT has a very simple answer to the question (i). In order to account for the usual observation that comprehension can be perfect while production is not, Smolensky (1996) assumes two kinds of constraints: (a) markedness constraints for forms and (b) linking (faithfulness) constraints - linking forms and meanings in an adequate way. Further, he assumes that the markedness constraints initially dominate the linking constraints. It is exactly under these conditions that we get the expected pattern.

For sake of illustration, let us go back to the example with two forms and two meanings (first article of this volume). We introduced the markedness constraint for forms $\mathrm{F}$ and the two linking constraints $\mathrm{F} \rightarrow \mathrm{M}$ and $* \mathrm{~F} \rightarrow * \mathrm{M}$ (see table 1 , p. 10). If $\{\mathrm{F}\}>>\{\mathrm{F} \rightarrow \mathrm{M}, * \mathrm{~F} \rightarrow * \mathrm{M}\}$ then comprehension is always correct (interpreting $f_{1}$ as $m_{1}$ and $f_{2}$ as $m_{2}$ ). However, the production perspective sometimes gives the wrong result. This is because of the dominance of the markedness constraint $\mathrm{F}$, and it gives the result that all meanings $m_{i}(i=1,2)$ are expressed by the simpler form $f_{1}$.

Interestingly, the opposite pattern of delayed comprehension is also possible. In this case we have to assume an incomplete system of linking constraints that outranks the system of markedness constraints. A very simple 
example is $\{\mathrm{F} \rightarrow \mathrm{M}\}>>\{\mathrm{F}\}$. In this case $m_{1}$ produces $f_{1}$ and $m_{2}$ produces $f_{2}$. However, while $f_{1}$ is always interpreted correctly as $m_{1}$ the form $f_{2}$ comes out as ambiguous. It can be interpreted both as $m_{1}$ and $m_{2}$, and this constitutes a case of delayed comprehension.

The research question (ii) is much more difficult to answer. The difficulty arises from the fact that there is not only one potential mechanism to overcome the gap between comprehension and production. There are at least two such mechanisms, and I will consider them in correspondence with the two ways of viewing bidirection discussed earlier. The first mechanism is based on an OT learning mechanism that re-ranks the involved constraints. That's exactly Smolensky's view as taken in Smolensky (1996). The second mechanism is a mechanism of maturation resulting in a processing system that integrates the comprehension and the production perspective. The resulting integrated system can be either the symmetric system of bidirectional OT or an asymmetric version such as proposed by Joshi and worked out by Zeevat (2000).

In a slightly different formulation, the first mechanism is realizing the diachronic view of bidirection where bidirectional optimization takes place offline (during language acquisition) and leads to some kind of fossilizing optimal form-meaning pairs. In contrast, the second mechanism presumes bidirectional optimization as a psychologically realistic online mechanism. According to this online/synchronic view, speakers (hearers) optimize bidirectionally and take into account hearers (speakers) when selecting (interpreting) a referring expression. In the following I will consider some experimental investigations that shed a light on the empirical adequacy of these two positions.

\subsection{The Pronoun Interpretation Problem}

In a recent research article Hendriks \& Spenader (2005/2006) give a new interpretation of children's delay of the comprehension of pronouns (see also Hendriks, Rijn, \& Valkenier, 2007). I discuss the validity of their interpretation and present an alternative account in terms of iterated learning.

A series of experiments has shown that children make errors in interpreting pronouns as late as age 6;6, yet correctly comprehend reflexives from the age of 3;0 (e.g. Chien \& Wexler, 1990; McKee, 1992; Koster, 1993; Spenader, Smits, \& Hendriks, 2007). For example, children were confronted with a context where two boys, Bert and Paul, are introduced, and the following sentences were given:

(2) a. Bert is washing himself

b. Bert is washing him 
Sentences like (2a) are correctly understood from a young age (95\% of the time according to some studies). However, children misinterpret the pronoun in (2b) as coreferring with the subject about half the time. Hence, it seems that children did not yet realize that the coreferring reading of (5b) must be blocked given the existence of the sentence (2a) which clearly has the coreferring reading.

Contrasting with the comprehension data, language production experiments consistently have shown that children do not have problems in producing reflexives or pronouns correctly. For example, Bloom et al. (1994) demonstrated that even in the youngest age groups investigated (ranging from 2;3 to 3;10) the children consistently used the pronoun to express a disjoint meaning, while they used the reflexive to express a coreferential interpretation. It can be concluded from the production data that children have competence of binding principles. Why they don't use this knowledge in comprehension?

I cannot go into all the different theoretical proposals concerning the pronoun interpretation problem. Instead, I will be mainly concentrated on the possibilities opened by OT pragmatics. Recently, several authors have agued that the observed delay in comprehension can be explained by assuming that children are only able to consider their own perspective, whereas adult hearers are able to simultaneously take into account the perspective of the speaker (deHoop \& Kramer, 2005/2006; Hendriks \& Spenader, 2005/2006; Hendriks, Rijn et al., 2007).

As explained at the beginning of this section it is possible to account for the delay of comprehension by assuming an incomplete system of linking constraints that outranks the system of markedness constraints for forms, for instance the system $\{\mathrm{F} \rightarrow \mathrm{M}\}>>\{\mathrm{F}\}$. In the concrete case of pronoun/reflexive interpretation $f_{1}$ stands for the reflexive, $f_{2}$ for the pronoun, $m_{1}$ for the coreferential interpretation and $m_{2}$ for the disjoint interpretation. The markedness constraint $\mathrm{F}$ prefers he reflexive over the pronoun and can be read as "referential ecomomy" (see Burzio, 1998). The linking constrain $\mathrm{F} \rightarrow \mathrm{M}$ excludes the reflexive from the disjoint interpretation - that's just the binding principle A (a reflexive must be bound locally) expressed as a violable constraint. Figure 3 shows the preferences between the four possible form meaning pairs arising from the system. 


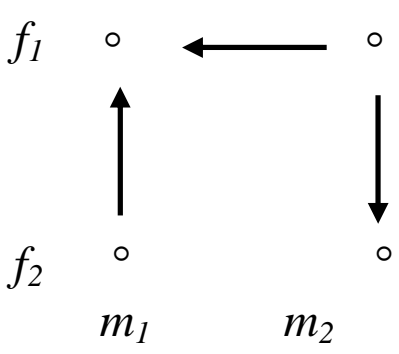

Figure 3: Diagram illustrating the pronoun interpretation problem. It shows the preferences between the four form-interpretation pairs based on the system $\{\mathrm{F} \rightarrow \mathrm{M}\}>>\{\mathrm{F}\}$ of ranked constraints

Assume now that children begin with unidirectional optimization. In the case of production everything goes right: the meanings $m_{1}$ and $m_{2}$ are expressed by $f_{1}$ and $f_{2}$, respectively. However, in case of comprehension the form $f_{2}$ (the pronoun) exhibits an ambiguity: both he interpretation $m_{1}$ and $m_{2}$ are optimal taken the interpretive perspective for optimization. And that's exactly the expression of the pronoun interpretation problem.

Optimizing bidirectionally inherently involves reasoning about alternatives not present in the current situation. In the present case a child who is hearing $f_{2}$ (a pronoun) must reason what other non-expressed forms the speaker could have used. It can realize then that a coreferential meaning $m_{1}$ is better expressed with $f_{1}$ (a reflexive). Then, by a process of elimination, the child must realize the pronoun should be interpreted as disjoint meaning $m_{2}$ and this resolves the ambiguity. Since the ability to optimize bidirectionally may be a skill acquired relatively late, this idea gives a plausible explanation of the lag in acquisition.

Summarizing, the online processing account of Hendriks \& Spenader (2005/2006) provides a new way to explain children's delay of the comprehension of pronouns. What's essential for this solution is the hypothesis that the hearer has to take a potential speaker into account. Thus, the authors are able to derive principle B effects (pronouns are free) from principle A alone, through bidirectional optimization. The approach nicely combines a pragmatic explanation with a processing account (lack of processing resourses). Besides the stipulation of the constraints and their ranking no other stipulations are required.

However, there are also some arguments that challenge the discussed view. First at all there is the question of constraint grounding. Other systems of 
constraints are conceivable and successfully used in the literature (see, e.g., Levinson, 2000; Mattausch, 2004). Further, there is no answer on the question why the particular ranking $\{\mathrm{F} \rightarrow \mathrm{M}\}>>\{\mathrm{F}\}$ is assumed. Another problem has to do with children's abilities for mind reading (theory of mind) that is explicitly assumed in Hendriks' and Spenader's approach. The assumption of mind reading as a prerequisite for making the transition to bidirectional reasoning has the consequence that there should be strict correlations between the behaviour in standard tests of theories of mind (see Perner, Leekam, \& Wimmer, 1987) and the behaviour in tasks involving bidirectionality (such as pronoun interpretation). Unfortunately, such strict correlations never were found (Flobbe, Verbrugge, Hendriks, \& Krämer, 2007). Further, mind reading requires awareness of other conversation participant's choices. Hence, it is based on controlled rather than automatic processing. However, pronoun processing appears to be automatic rather than controlled. There is no explicit hint for mind reading capacities in such tasks.

In the following subsection I will propose an alternative account that can describe the same kind of data and in addition has some conceptual advantages.

\subsection{Pronoun interpretation and related task: individual fossilization}

In section 2, I described an approach to fossilization and I made a distinction between individual fossilization (or routinization) and cultural fossilization. Cultural fossilization was successfully used by Mattausch and Jäger (Jäger, 2004; Mattausch, 2004). I will consider now individual fossilization in connection with the pronoun interpretation problem.

In the informal description given here the focus is on pointing out the differences to the processing account provided by Hendriks \& co. Let's start with Hendrik's initial system $\{\mathrm{F} \rightarrow \mathrm{M}\}>>\{\mathrm{F}\}$. In order to apply OT learning theory we assume that a complete system of constrains is present in a background of equally ranked constraints. The following system which is functionally equivalent with the system described before is used: $\{\mathrm{F} \rightarrow \mathrm{M}\}>>$ $\{\mathrm{F}\}>>\mathrm{F} \rightarrow * \mathrm{M}, * \mathrm{~F} \rightarrow \mathrm{M} * \mathrm{~F} \rightarrow * \mathrm{M}\}$. The learning rule then says: promote constraints that favour wanted behaviour over unwanted, demote constraints that favour unwanted behaviour over wanted. If a competent adult acts as speaker and the child as hearer, then this learning rules lead to the promotion of ${ }^{*} \mathrm{~F} \rightarrow{ }^{*} \mathrm{M}$ (principle B). Figure 4 illustrates the transfer between the two systems. ${ }^{6}$

${ }^{6}$ Alternatively, we could start with the system $\left\{{ }^{*} \mathrm{~F}, * \mathrm{M}\right\}>>\left\{\mathrm{F} \rightarrow \mathrm{M}, \mathrm{F} \rightarrow{ }^{*} \mathrm{M},{ }^{*} \mathrm{~F} \rightarrow \mathrm{M}\right.$, $* \mathrm{~F} \rightarrow * \mathrm{M}\}$. The two dominating constraint $* \mathrm{~F}$ and $* \mathrm{M}$ express that $f_{2}$ (pronoun) is the preferred form and that $m_{2}$ (disjoint interpretation) is the preferred interpretation. The linking constraints cancel each other. Then it can be shown that iterated learning leads to different stages of development. First the principle $\mathrm{A}$ is evolving if the plausible 

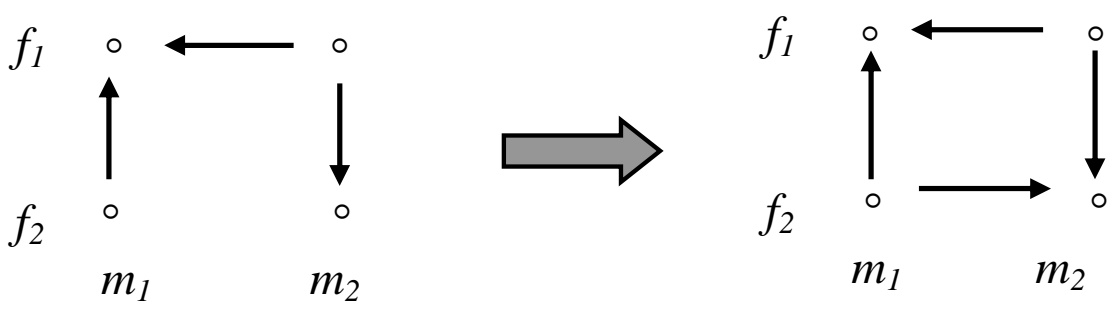

Figure 4: Transformation between two systems of ranked constraints provided by individual fossilization

It is obvious that this transfer is dependent of parameters of use. Hence, we expect frequency effects when the fossilization mechanism is at work. Further, we would expect no significant differences between the comprehension of pronouns and the comprehension of reflexives. The reason is that their processing loads are not significantly different. Hendriks' online view of processing (involving bidirection) conflicts with both hypotheses. It suggests a domain-independent transition from the unidirectional to the bidirectional case. Consequently, we shouldn't expect significant effects of use (frequency effects). Further, for adult subjects we should expect significant differences in processing between pronouns and reflexives, since the pronoun requires bidirectional processing but the reflexive does not.

I think both hypotheses supporting the fossilization view can be confirmed. Though there is no direct verification of the second hypothesis at the moment, I think in the light of the eye tracking investigations of Karabanov, Bosch, \& König (to appear) it is not probable that the comprehension of pronouns takes significantly more time than the comprehension of reflexives assuming comparable conditions. For the first hypothesis, it's important to see that there are some other domains which realize the same structural relations as exhibited in the case of pronoun interpretation shown in Figure 3. Consider first the domain of natural language quantifiers and consider dual quantifiers such as some $(A)$ and all(A), where A stand for a certain restrictive term. Logically, all $(A)(B)$ has the set inclusion interpretation stating $A \subseteq B$, and some $(A)(B)$ has an interpretation expressing nonempty intersection $A \cap B \neq \varnothing$. Of course, this

stipulation is made that $\mathrm{P}\left(m_{2}\right)>\mathrm{P}\left(m_{1}\right)$. Hence we have a motivation why the system of preferences as given on the left hand site of Figure 4 appears - it reflects delayed comprehension - instead of a system exhibiting delayed production. Only later the principle B becomes dominant, giving the preferences shown on the right hand site of Figure 4. 
interpretation does not exclude the set inclusion reading. It's the scalar implicature that excludes this interpretation - leading to a some_but_not_all interpretation. The ordering of all form interpretation pairs given in Figure 3 can be applied to the quantifier case when we assume that $f_{1}$ stands for all, $f_{2}$ for some, $m_{1}$ for the set inclusion interpretation, and $m_{2}$ for the some_but_not_all reading. The markedness constraint $\mathrm{F}$ now prefers all over some. We can see that as a realization of the strongest meaning hypothesis (Dalrymple et al., 1998). Further, the dominating constraint $\mathrm{F} \rightarrow \mathrm{M}$ expresses the meaning postulate for all, and the potential constraint $* \mathrm{~F} \rightarrow * \mathrm{M}$ expresses the scalar implicature for some.

The first systematic investigation of the acquisition of scalar implicature can be attributed to Noveck (2001). From his experiments it can be concluded that young children initially treat a relatively weak term logically before becoming aware of its pragmatic potential, and that, in this respect, "children are more logical than adults" (Noveck, 2001: 165). Concluding, we can speak of delayed comprehension of the pragmatic potential of the weak quantifier.

Another domain where we find similar effects is the interpretation indefinite expressions. In several languages it has been observed that indefinite noun phrases such as a boy take on different interpretations depending on whether they appear in a scrambled or unscrambled word ordering (e.g. de Hoop \& Krämer, 2005; Unsworth, 2005). Adults interpret unscrambled indefinites $\left(f_{1}\right)$ as 'non-specific' $\left(m_{1}\right)$ whereas they interpret scrambled indefinites $\left(f_{2}\right)$ as 'specific' $\left(m_{2}\right)$. Again we find a delayed comprehension effect: children interpret scrambled indefinites in both ways. Only later they realize that the 'specific' interpretation is the proper one.

In a recent article Hendriks et al. (2007) discuss the results of diverse experiments in different domains and conclude that children seem to differ in the ages at which they provide adult-like responses for particular linguistic forms.

Whereas from the age of 6 or 7 on children start to interpret pronouns correctly, children until roughly 11 years old select a non-adult meaning for indefinite objects (Unsworth, 2005), and many 10- and 11-year-olds do not draw a scalar implicature where most adults would (Noveck, 2001). This suggests that bi-directional optimization is not a general strategy that has to be learned by children in one step, but rather that the possibility of bi-directional optimization is dependent on the frequency of use of the relevant production rules. (p. 1893)

Hence, the first hypothesis suggested above - predicting a domain-independent transition from the unidirectional to the bidirectional view - seems to be 
falsified. And this might be a powerful argument supporting the fossilization view.

Thought the domain independence of he transfer from unidirectional to bidirectional processing is a natural consequence of the online processing view, it is not a necessary consequence. Hendriks et al. (2007) provide an improvement of their online processing view in order to describe the empirically found domain dependency. This improvement is formulated in terms of the ACT-R model (Anderson \& Lebiere, 1998; Anderson et al., 2004).

ACT-R understands itself as an integrated theory of the mind. Different from Smolensky's (Smolensky \& Legendre, 2006) theory of harmonic mind which sees the symbolic part (i.e., OT) as a high-level description of the neural realm, ACT-R is a hybrid theory that relates different symbolic modules with certain subsymbolic processes. These subsymbolic processes serve to guide the selection of rules to fire as well as the internal operations of modules and much of learning.

Hendriks et al. (2007) model unidirectional and bidirectional OT in terms of the ACT-R model. In this model bidirectional optimization is described as the serial application of two unidirectional processes of optimization. A crucial property of ACT-R is the assumption that actions take time to perform and that performance is limited by the serial processing bottleneck. Since bidirectional optimization needs much more processing resources than unidirectional optimization does, a process of production compilation ${ }^{7}$ comes in increasing the processing efficiency. The result of product compilation conforms to an instance based kind of automatization (Logan, 1988). I think what is described here comes very close to the idea of fossilization. Whereas fossilization leads to the introduction of new linking constraints product compilation leads to the generation of new productions who describe the results of certain bidirectional actions.

\subsection{Choosing the right referring expression}

The standard case of production/comprehension asymmetries is delayed production. Comprehension can be perfect while production is not. A good example is given by production and understanding of R-expressions and pronouns as illustrated in (3).

\footnotetext{
${ }^{7}$ In production compilation, two existing production rules are integrated into one new production rule. Production compilation occurs when two existing production rules are repetitively executed in sequence.
} 
(3) Discourse context: A woman is waiting at the corner. Her girl is eating an ice cream cone.

a. She wears a red shirt.

b. The woman wears a red shirt.

The interpretation of the pronoun in (3a) clearly refers to the discourse topic (the girl). If we want to express the alternative meaning as in (3b) we cannot use the pronoun. Interestingly, young children very often produce such subject pronouns when intending to refer to non-topics. Karmiloff-Smith (1985) found this pattern of production in children until the age of 6 .

I have already mentioned that the phenomenon can be modeled by assuming markedness conventions that initially dominate linking constraints. Figure 5 shows the corresponding diagram. Hereby, $f_{1}$ stands for the pronoun and $f_{2}$ for an R-expression. Further, $m_{1}$ is the interpretation referring to the topicalized discourse referent while $m_{2}$ refers to the non-topicalized one. F can be seen as referential economy (preferring pronouns to R-expressions) and $\mathrm{F} \rightarrow \mathrm{M}$ expresses the preference for pronouns to be interpreted as the topic of the discourse.

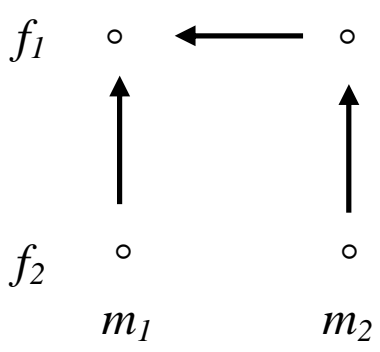

Figure 5: Diagram illustrating the pronoun production problem. It shows the preferences between the four form-interpretation pairs based on the system $\{\mathrm{F}\}>>$ $\{\mathrm{F} \rightarrow \mathrm{M}\}$ of ranked constraints

Using unidirectional optimization, the diagram describes the OT system of an agent who can properly understand pronouns and R-expressions but who overuse pronouns when intending to refer to non-topics.

The two considered models now make different assumptions for describing the transfer from the child system to the adult system. The online processing model handles the production problem by assuming that the producer takes the hearer into account and begins to reason bidirectionally at some point of development. In contrast, the fossilization view says that unidirectional 
optimization is sufficient if it is assumed that the relevant information has been fossilized at some part of the human development.

In a recent research article, Hendriks, Englert, \& Wubs (2007) argue that the investigation of elderly adults could decide between the two models. Elderly adults possess the required pragmatic and grammatical knowledge to select and interpret referring. However, their linguistic performance can be defective, due to a decreasing working memory capacity. And indeed, the authors found that elderly adults produce non-recoverable pronouns significantly more often than young adults when referring to the old topic in the presence of a new topic. With respect to the comprehension task, no significant differences were found between elderly and young adults.

Obviously, this experimental outcome is a great problem for the fossilization view, since a stipulation of a mechanism of 'de-fossilization' does not make any sense in the present context. Hence, the assumption that the speaker takes the hearer into account is well motivated for such examples. Zeevat (2000) has argued for this kind of active, creative processes.

However, there is also a problem for the bidirectional processing view. It says that both the speaker takes the hearer into account and, vice versa, the hearer takes the speaker into account. If that is right, then the same argumentation that is given in the paper by Hendriks, Englert, \& Wubs (2007) can be applied for the delayed comprehension experiments discussed in the previous subsections. Thought I don't know of any experiments with elderly people concerning the delayed comprehension task, I bet more than my finger that the behavior of elderly people does not go down to that of young children in the relevant respects. Hence what we can conclude from these experiments is an asymmetry of processing: the speaker takes the hearer into account but not necessarily vice versa. This is actually Zeevat's (2000) view of making a distinction between the active and creative process of production and the rather passive process of interpretation. ${ }^{8}$ The idea of fossilization is needed in order to account for the delayed comprehension data.

8 "The situation can be fruitfully compared to the habit of hiding easter eggs for one's children. The parents engaged in hiding the eggs balance the amount of effort with the desired amount of difficulty in finding the egg. (They also picture the child looking for it and try to keep it possible for the child of finding the egg, without spoiling the fun.) For the child it is another matter. They just have to throw in the effort required for finding the eggs. Not more of course, but definitely not less. It is not a complicated balancing act.” (Zeevat 2000: 245) 


\section{Conclusions}

The aim of this article was to close the gap between experimental pragmatics and neo-Gricean theories of pragmatics as formulated in OT pragmatics. I have argued that OT pragmatics has the potential to account both for the synchronic and the diachronic perspective in pragmatics. I further have pointed out that the concept of fossilization can help to understand the idea of naturalization and (cultural) embodiment in the context of natural language interpretation.

Concerning modern pragmatic theories such as RT and Levinson's theory of presumptive meanings, the conflict between effort minimization and effect maximization is resolved in different ways. In a certain sense, the crux of both approaches can be translated in OT pragmatics by making use of particular linking constraints. This translation makes the advantage of both approaches visible: both conform to the incremental, online character of natural language interpretation. $^{9}$

In the last part of the paper I have discussed recent work about the phenomenon of delayed comprehension and delayed production. This is a phenomenon which was not discussed within experimental pragmatics, though the importance of the problem was clearly recognized within OT pragmatics. I have discussed two models which conceptualized bidirection in different ways: the online processing model and the fossilization account. I have argued that neither of these extreme views gives a complete fit to the empirical data when taken per se. While it is obvious that fossilization phenomena are real to some extent it can be argued that a restricted online version of bidirection is correct: speakers optimize bidirectionally and take the hearer into account when calculating the optimal expression; in contrast, hearers normally do not take the speaker into account when calculating the optimal interpretation.

\section{References}

Anderson, J. R., Bothell, D., Byrne, M. D., Douglass, S., Lebiere, C., \& Qin, Y. (2004). An integrated theory of the mind. Psychological Review, 111, 1036-1060.

\footnotetext{
${ }^{9}$ In discussing processing characteristics, incrementality and automaticity of processing have to be discriminated. Whereas automaticity of processing implicates the incremental character of processing the opposite is not true: incrementality does not implicate automatic processing. RT explains the incremental character of processing and has good reasons for assuming controlled processing in order to account for the processing of conversational implicatures. That's different from Levinson's account which assumes automatic processing for generalized conversational implicatures. It seems that RT is better justified on empirical grounds (cf. Noveck \& Sperber, 2005).
} 


\section{Reinhard Blutner}

Anderson, J. R., \& Lebiere, C. (1998). The Atomic Components of Thought. Mahwah, NJ.: Erlbaum.

Atlas, J. D. (2005). Logic, Meaning, and Conversation: Semantical Underdeterminacy, Implicature, and Their Interface. Oxford: Oxford University Press.

Atlas, J. D., \& Levinson, S. C. (1981). It-clefts, informativeness and logical form. In P. Cole (Ed.), Radical Pragmatics (pp. 1-61). New York: Academic Press.

Axelrod, R. (1984). The evolution of co-operation. London: Penguin.

Beaver, D., \& Lee, H. (2004). Input-output mismatches in OT. In Palgrave/Macmillan (Ed.), Optimality Theory and Pragmatics. Houndmills, Basingstoke, Hampshire.

Benedict, H. (1979). Early Lexical Development: Comprehension and Production. Journal of Child Language, 6, 183-200.

Benz, A. (2003). Partial Blocking, associative learning, and the principle of weak optimality. In J. Spenader \& A. Eriksson \& Ö. Dahl (Eds.), Proceedings of the Stockholm Workshop on Variation within Optimality Theory (pp. 150-159). Stockholm.

Benz, A. (2006). Partial blocking and associative learning. Linguistics and Philosophy, 29, 587-615.

Biro, T. (2006). Finding the right words: Implementing Optimality Theory with simulated annealing. University of Groningen, Groningen.

Bloom, P., Barss, A., Nicol, J., \& Conway, L. (1994). Children's knowledge of binding and coreference: Evidence from spontaneous speech. Language, 70, 53-71.

Blutner, R. (1998). Lexical pragmatics. Journal of Semantics, 15, 115-162.

Blutner, R. (2004). Nonmonotonic inferences and neural networks. Synthese (Special issue Knowledge, Rationality and Action), 142, 143-174.

Blutner, R. (2006). Embedded implicatures and optimality theoretic pragmatics. In Torgim Solstad \& A. Grønn \& D. Haug (Eds.), A Festschrift for Kjell Johan Scebø: in partial fulfilment of the requirements for the celebration of his 50th birthday. Oslo.

Blutner, R. (2007). Optimality Theoretic Pragmatics and the Explicature/Implicature Distinction. In N. Burton-Roberts (Ed.), Pragmatics (pp. 67-89). Houndmills, Basingstoke, Hampshire: Palgrave/MacMillan.

Blutner, R., Borra, E., Lentz, T., Uijlings, A., \& Zevenhuijzen, R. (2002). Signalling games: Hoe evolutie optimale strategieen selecteert, Handelingen van de 24ste NederlandsVlaamse Filosofiedag. Amsterdam: Universiteit van Amsterdam.

Burzio, L. (1998). Anaphora and soft constraints. In P. Barbosa \& D. Fox \& P. Hagstrom \& M. McGinnis \& D. Pesetsky (Eds.), Is the best good enough? Cambridge, Mass.: The MIT Press.

Carston, R. (2002). Thoughts and Utterances: The Pragmatics of Explicit Communication. Oxford: Blackwell. 
Chien, Y.-C., \& Wexler, K. (1990). Children's knowledge of locality conditions on binding as evidence for the modularity of syntax and pragmatics. Language Acquisition, 13, 225295.

Chierchia, G. (2004). Scalar implicatures, polarity phenomena, and the syntax/pragmatics interface. In A. Belletti (Ed.), Structures and Beyond (pp. 39-103). Oxford: Oxford University Press.

Clark, E. V. (1993). The Lexicon in Acquisition. Cambridge: Cambridge University Press.

Cole, P. (1975). The synchronic and diachronic status of conversational implicature. In P. Cole \& J. L. Morgan (Eds.), Syntax and Semantics, Volume 3: Speach Acts (pp. 257288). San Diego, Cal.: Academic Press, Inc.

Dalrymple, M., Kanazawa, M., Kim, Y., Mchombo, S., \& Peters, S. (1998). Reciprocal expressions and the concept of reciprocity. Linguistics and Philosophy, 21, 159-210.

de Hoop, H., \& Krämer, I. (2005). Children’s Optimal Interpretations of Indefinite Subjects and Objects. Language Acquisition, 13, 103-123.

deHoop, H., \& Kramer, I. (2005/2006). Children's Optimal Interpretations of Indefinite Subjects and Objects. Language Acquisition, 13, 103-123.

Flobbe, L., Verbrugge, R., Hendriks, P., \& Krämer, I. (2007). Children's application of Theory of Mind in reasoning and language.Unpublished manuscript, University of Groningen \& Radboud University Nijmegen.

Fodor, J. (1975). The Language of Thought. New York: Thomas Crowell.

Gazdar, G. (1979). Pragmatics. New York: Academic Press.

Geis, M., \& Zwicky, A. (1971). On invited inference. Linguistic Inquiry, 2, 561-579.

Hendriks, P., \& de Hoop, H. (2001). Optimality theoretic semantics. Linguistics and Philosophy, 24, 1-32.

Hendriks, P., Englert, C., Wubs, E., \& Hoeks, J. (2007). Age differences in adults' use of referring expressions.Unpublished manuscript, University of Groningen.

Hendriks, P., Hoop, H. d., Krämer, I., Swart, H. d., \& Zwarts, J. (to appear). Conflicts in Interpretation.

Hendriks, P., Rijn, H. v., \& Valkenier, B. (2007). Learning to reason about speakers' alternatives in sentence comprehension: A computational account. Lingua, 117, 1879_ 1896.

Hendriks, P., \& Spenader, J. (2005/2006). When production precedes comprehension: An optimization approach to the acquisition of pronouns. Language Acquisition, 13, 319348.

Hobbs, J., \& Martin, P. (1987). Local Pragmatics, Proceedings, International Joint Conference on Artificial Intelligence (pp. 520-523). Milan.

Horn, L. (1984). Towards a new taxonomy of pragmatic inference: Q-based and R-based implicature. In D. Schiffrin (Ed.), Meaning, form, and use in context: Linguistic applications (pp. 11-42). Washington: Georgetown University Press. 
Horn, L. (1989). A natural history of negation. Chicago: Chicago University Press.

Horn, L. (2004). Implicature. In L. Horn \& G. Ward (Eds.), Handbook of Pragmatics. Oxford: Blackwell.

Horn, L. (2005). Current issues in neo-Gricean pragmatics. Intercultural Pragmatics, 2, 191204.

Horn, L., \& Bayer, S. (1984). Short-circuited implicature: A negative contribution. Linguistics and Philosophy, 7, 397-414.

Jäger, G. (2002). Some notes on the formal properties of bidirectional optimality theory. Journal of Logic, Language and Information, 11, 427-451.

Jäger, G. (2004). Learning constraint sub-hierarchies. The bidirectional gradual learning Algorithm. In R. Blutner \& H. Zeevat (Eds.), Pragmatics and Optimality Theory. Houndmills, Basingstoke, Hampshire: Palgrave Macmillan.

Jakobson, R. (1941/1968). Child Language, Aphasia and Phonological Universals. The Hague: Mouton.

Jaszczolt, K. M. (to appear). Semantics and Pragmatics: The Boundary Issue. In C. Maienborn \& K. v. Heusinger \& P. Portner (Eds.), Semantics: An International Handbook of Natural Language Meaning. Berlin: Mouton de Gruyter.

Joshi, A. K. (1987). Generation - a new frontier of natural language processing? . Theoretical Issues in Natural Language Processing, 3, 181-184.

Karabanov, A., Bosch, P., \& König, P. (to appear). Eye Tracking as a tool for investigating the comprehension of referential expressions. In S. Featherston \& W. Sternefeld (Eds.), Roots: Linguistics in search of its evidential base. Berlin: De Gruyter.

Karmiloff-Smith, A. (1985). Language and cognitive processes from a developmental perspective. Language and Cognitive Processes, 1, 61-85.

Koster, C. (1993). Errors in Anaphora Acquisition. Unpublished Ph.D. Dissertation, Utrecht University, Utrecht.

Krifka, M. (1995). The Semantics and Pragmatics of Polarity Items. Linguistic Analysis, 25, 209-257.

Krifka, M. (2007). Approximate interpretation of number words: A case for strategic communication. In G. Bouma \& I. Krämer \& J. Zwarts (Eds.), Cognitive foundations of interpretation (pp. 111-126). Amsterdam: Koninklijke Nederlandse Akademie van Wetenschapen.

Levinson, S. (2000). Presumptive meaning: The theory of generalized conversational implicature. Cambridge, Mass.: MIT Press.

Logan, G. D. (1988). Toward an instance theory of automatization. Psychological Review, 95, 492-527.

Mattausch, J. (2004). On the Optimization \& Grammaticalization of Anaphora. Unpublished Ph.D. Thesis, Humboldt University, Berlin. 
McCawley, J. D. (1978). Conversational implicature and the lexicon. In P. Cole (Ed.), Syntax and Semantics 9: Pragmatics (pp. 245-259). New York: Academic Press.

McKee, C. (1992). A Comparison of Pronouns and Anaphors in Italian and English Acquisition. Language Acquisition, 2.

Morgan, J. L. (1978). Two Types of Convention in Indirect Speech Acts. In P. Cole (Ed.), Syntax and Semantics 9: Pragmatics (pp. 261-280). New York: Academic Press.

Noveck, I. (2001). When children are more logical than adults. Cognition, 78, 165-188.

Noveck, I. A., \& Sperber, D. (Eds.). (2005). Experimental Pragmatics. Houndmills, Basingstoke, Hampshire: Palgrave MacMillan.

Perner, J., Leekam, S. R., \& Wimmer, H. (1987). Three-year Olds’ Difficulty with False Belief: The Case for a Conceptual Deficit. British Journal of Developmental Psychology, 5, 125-137.

Rumelhart, D. E., Hinton, G. E., \& McClelland, J. L. (1986). A general framework for parallel distributed processing. In J. L. McClelland \& D. E. Rumelhart \& the-PDPResearch-Group (Eds.), Parallel Distributed Processing: Explorations in the Microstructure of Cognition 1. Cambridge, MA: MIT Press.

Russell, B. (2006). Against grammatical computation of scalar implicatures. Journal of Semantics, 23, 361-382.

Sæbø, K. J. (2004). Optimal interpretations of permission sentences. In D. de Jongh \& P. Dekker (Eds.), Proceedings of the 5th Tbilisi Symposium on Language, Logic and Computation (pp. 137-144). Amsterdam and Tbilisi.

Sauerland, U. (2004). Scalar implicatures in complex sentences. Linguistics and Philosophy, 27, 367-391.

Schneider, W., \& Shiffrin, R. M. (1977). Controlled and automatic human information processing. Psychological Review, 84, 1-66.

Smolensky, P. (1996). On the comprehension/production dilemma in child language. Linguistic Inquiry, 27, 720-731.

Smolensky, P., \& Legendre, G. (2006). The Harmonic Mind: From neural computation to optimality-theoretic grammar. Cambridge, Mass.: MIT Press.

Soames, S. (1982). How presuppositions are inherited: A solution to the projection problem. Linguistic Inquiry, 13, 483-545.

Spenader, J., Smits, E.-J., \& Hendriks, P. (2007). Coherent discourse solves the Pronoun Interpretation Problem.Unpublished manuscript, University of Groningen.

Sperber, D., Cara, F., \& Girotto, V. (1995). Relevance theory explains the selection task. Cognition, 57, 31-95.

Sperber, D., \& Wilson, D. (1986/1995). Relevance. Oxford: Basil Blackwell.

Stalnaker, R. (2006). Saying and meaning, cheap talk and credibility. In A. Benz \& G. Jäger \& R. Van Rooij (Eds.), Game Theory and Pragmatics (pp. 82-101): Palgrave MacMillan. 
Traugott, E. (1989). On the Rise of Epistemic Meanings in English: An Example of Subjectification in Semantic Change. Language 65, 31-55.

Traugott, E., \& Dasher, R. B. (2005). Regularity in Semantic Change. Cambridge: Cambridge University Press.

Unsworth, S. (2005). Child L2, Adult L2, Child L1: Differences and Similarities. Unpublished PhD Dissertation, Utrecht University.

Van Rooy, R. (2004). Signalling games select Horn strategies. Linguistics and Philosophy, 27, 493-527.

Wilson, D. (2003). Relevance and Lexical Pragmatics. Italian Journal of Linguistics/Rivista di Linguistica, 15, 273-291.

Wilson, D., \& Matsui, T. (1998). Recent approaches to bridging: Truth, coherence, relevance. UCL Working Papers in Linguistics 10

Zeevat, H. (2000). The asymmetry of optimality theoretic syntax and semantics. Journal of Semantics, 17, 243-262.

Zeevat, H. (2002). Explaining presupposition triggers. In K. van Deemter \& R. Kibble (Eds.), Information Sharing (pp. 61-87). Stanford: CSLI Publications.

Zeevat, H. (2007). Optimal Interpretation as an Alternative to Gricean Pragmatics Unpublished manuscript, Universiteit van Amsterdam.

Zwarts, J. (2003). Lexical Competition: 'Round' in English and Dutch. In P. Dekker \& R. van Rooy (Eds.), Proceedings of the Fourteenth Amsterdam Colloquium (pp. 229-234). Amsterdam: ILLC.

Zwarts, J. (2006). Om en rond: Een semantische vergelijking. Nederlandse Taalkunde, 11, 101-123. 